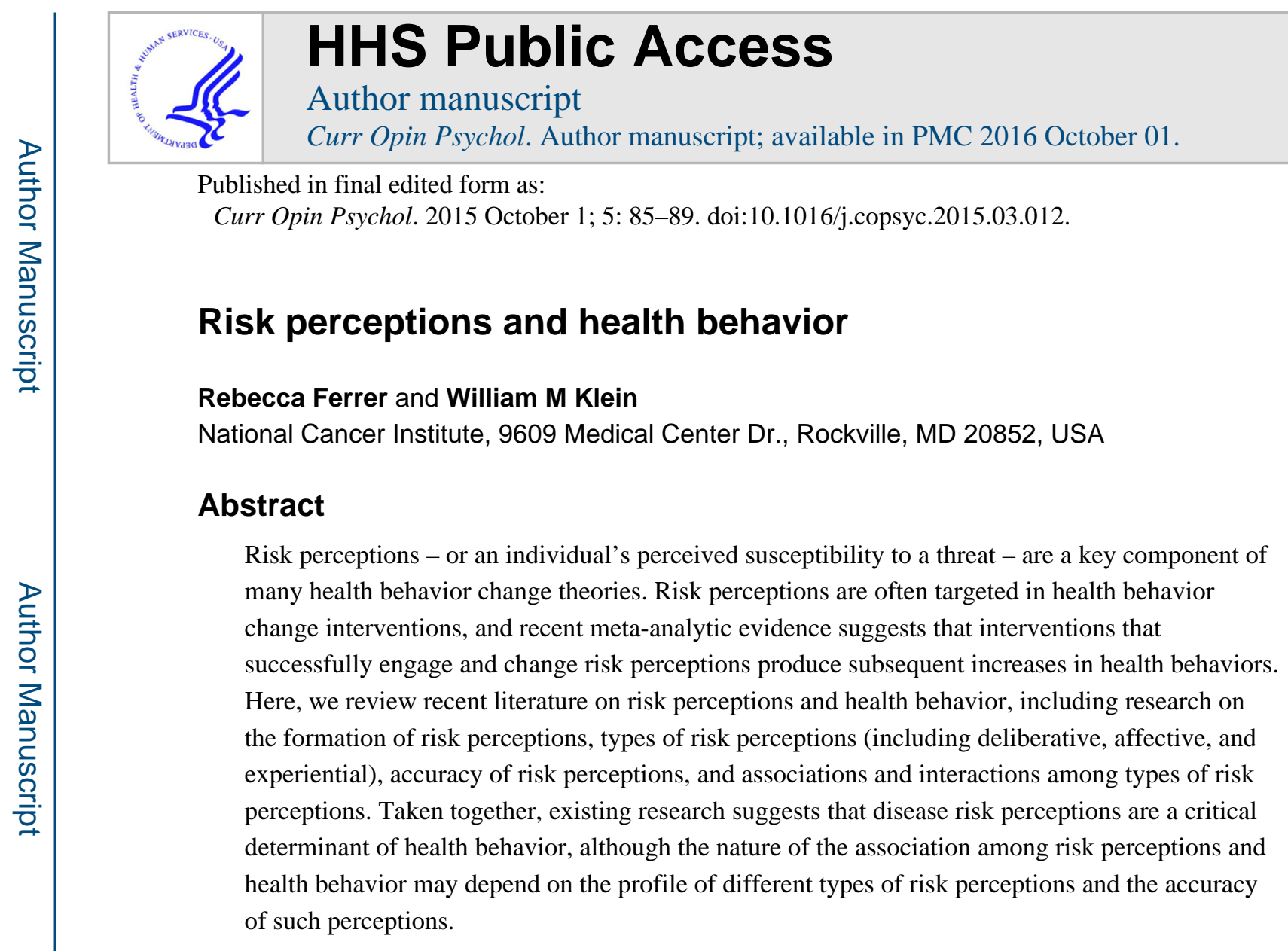

In health decision-making, individuals are expected to navigate choices involving weighing risk for consequences with benefits of action. Behaviors contributing to disease initiation and progression are often pleasurable (e.g., smoking or overeating). Motivation to forgo such pleasurable behaviors, or engage in inconvenient preventive behaviors, is believed to be driven to some extent by beliefs about the probability that a health consequence will occur [1-2]. Correlational evidence supports an at-least-modest association between risk perceptions and health behaviors [3-4].

Theory-guided health behavior change interventions and health communications often target risk perceptions toward the end of changing health behaviors [5]. A recent meta-analysis of experimental evidence supports the role of risk perceptions in health decision-making; when interventions successfully change risk perceptions, health behavior change often results [6]. Risk perceptions may also have implications for overall well-being as threats unfold. For example, prospective evidence demonstrates that, among individuals with high cancer risk perceptions, subsequent cancer diagnosis is associated with poorer well-being; however, among those with low cancer risk perceptions, subsequent cancer diagnosis is unrelated to well-being [7].

Publisher's Disclaimer: This is a PDF file of an unedited manuscript that has been accepted for publication. As a service to our customers we are providing this early version of the manuscript. The manuscript will undergo copyediting, typesetting, and review of the resulting proof before it is published in its final citable form. Please note that during the production process errors may be discovered which could affect the content, and all legal disclaimers that apply to the journal pertain. 


\section{Formation of risk perceptions}

A growing body of literature has probed how risk perceptions are formed. Although risk perceptions can be optimistic (i.e., low) or pessimistic (i.e., high), they are empirically and conceptually distinct from general dispositional optimism, in part because they are domainspecific [8]. Indeed, evidence suggests that, in the general population, individuals are able to differentiate among specific threats when forming risk perceptions [9]. Moreover, several studies suggest that dispositional and domain-specific optimism may interact in ways with important implications for health [10]. For example, individuals high in dispositional optimism who also have optimistic risk perceptions regarding a looming threat may be more likely to minimize the threat's severity and less likely to seek additional health information [11].

Given that risk perceptions involve incorporating numeric information about a threat, the ability to produce, understand, and use numeric information plays an important role in the formation and use of risk perceptions [12]. Indeed, evidence shows that individuals who are highly numerate are more likely to retrieve and use numerical principles in decision-making, rendering them less susceptible to biases related to risk perception and decision-making, and less likely to incorporate irrelevant information into risk perceptions [13]. However, evidence suggests that risk perceptions are reflective of not only numeric information, but also information regarding personal experiences. For example, enactment of precautionary behavior results in subsequent, appropriate reductions in risk perception [14], and engaging in risky behaviors is associated with appropriately higher risk perceptions [15]. Moreover, risk perceptions are influenced by what information is most salient or available to an individual [16]. For example, individuals perceive their risk for disease to be higher when someone in their family has been diagnosed with a disease [17]. Although factors like family history arguably provide some relevant information about actual susceptibility to disease, other salient information also plays a role in risk perception formation. For example, risk perceptions are often influenced by the frequency with which a threat is represented in media exposure [18].

Risk perceptions are also reliably influenced by contextual factors. For example, as looming threats become more immediate, risk perceptions tend to become more pessimistic [19]. Risk perceptions also tend to be higher when a health threat is seen as uncontrollable or dreaded [18]. Moreover, affective contextual factors play a critical role; individuals experiencing anger (a high certainty and control emotion) tend to have more optimistic risk perceptions, whereas those experiencing fear (a low certainty and control emotion) tend to have more pessimistic risk perceptions [20]. General affect can also influence the formation of risk perceptions. For example, distress is associated with higher risk perceptions [21], and depressed individuals may be more likely to adjust their risk perception estimates in response to health information than non-depressed individuals [22]. These tendencies have important implications for the formation of risk perceptions in a health context, particularly given that many health threats and clinical care contexts evoke strong emotions [23].

In sum, risk perceptions are threat-specific, rather than reflecting a general sense of optimism or pessimism. Although risk perceptions incorporate numeric information, a

Curr Opin Psychol. Author manuscript; available in PMC 2016 October 01. 
number of additional factors contribute to their formation, including personal experiences, salience of available examples, and affective factors.

\section{Types of risk perceptions}

Classic health behavior theories largely treat risk perceptions as deliberatively-derived judgments, and research synthesized thus far has fit this conceptualization. Deliberative risk perceptions are systematic, logical, and rule-based [24, 25]. Theories that emphasize deliberative risk perceptions suggest that an individual relies on a number of reason-based strategies to derive an estimate of the likelihood that the negative outcome will occur. Deliberative risk perceptions are usually absolute (e.g., percentage likelihood of disease) or comparative (e.g., likelihood of disease compared to others).

However, recent models of risk perception and decision-making have highlighted the divide between 1) deliberative and 2) affective or experiential components [26-28]. Affective risk perceptions refer to affect associated with risk. Affect has been established as an essential determinant of optimal judgment and decision-making [29], and is a critical component of judgments involving risk and uncertainty [27]. Worry or anxiety about a threat is considered to be an affective analogue to deliberative risk perceptions [27]. Meta-analytic evidence demonstrates that affective risk perceptions are related to preventive behaviors [30], and that interventions that successfully target these perceptions produce subsequent changes in behavior [6].

Experiential risk perceptions refer to rapid judgments made by integrating deliberative and affective information [31-32]. Consistent with existing terminology and theory [33], experiential risk perceptions refer to the contents of the perception as opposed to the process through which the perception is derived; thus, they are by definition consciously accessible. For example, an individual is consciously aware that her intuition or "gut" is telling her she is vulnerable to cancer, even if she has no conscious access to the processes that contributed to the formation of that judgment. Examples of experiential risk perceptions include gutlevel assessments of vulnerability (e.g., "how vulnerable do you feel?" [34] or gistrepresentations of risk [35]. Experiential risk perceptions are often more predictive of intentions or behavior than are deliberative risk perceptions [34, 36].

Critically, existing frameworks tend to combine or conflate affective and experiential components, or focus on one over the other as the non-deliberative component [26, 28, 37]. However, evidence suggests these are empirically distinct not only from deliberative components but also from one another [38-41].Thus, a more fine-grained and accurate distinction among these three types of risk perception - deliberative, affective, and experiential - can improve the predictive value of existing and emerging frameworks, and help applied researchers and practitioners to more effectively target the active ingredients necessary to facilitate behavior change.

\section{Accuracy of risk perceptions}

The formation of accurate - or inaccurate - risk perceptions may have important consequences for health. Although low risk perceptions are by definition optimistic, if an 
individual is indeed at low risk for a disease threat, those risk perceptions are also realistic. However, often individuals believe themselves to be at lower risk for outcomes than is warranted when examining their objective risk; this phenomenon is termed "unrealistic optimism" [42]. Note that accuracy of risk perceptions depends on measurement; an individual's risk perceptions regarding the same disease can be simultaneously pessimistic and optimistic when assessed with absolute and comparative measures, respectively [43]. For example, a woman with objectively high risk of breast cancer can estimate she has a $70 \%$ chance of breast cancer (an unrealistically pessimistic absolute estimate), but simultaneously report she is at lower risk than other women her age (an unrealistically optimistic comparative estimate). Unrealistic optimism, particularly as a comparative assessment, is quite prevalent in the general population [44].

Evidence regarding the implications of unrealistic optimism is mixed. Some studies suggest that unrealistic optimism yields lower motivation to engage in health protective behaviors that would mitigate risk [45-46], and unrealistic optimism has been linked to objective negative health outcomes [47-48]. However, other studies have linked unrealistic optimism to positive health outcomes [49-51]. Despite mixed evidence regarding implications, the extant literature clearly suggests that risk perceptions can be unrealistically optimistic, and that this is a fairly common bias.

\section{Associations and interactions among types of risk perceptions}

Importantly, existing models do not directly address the possibility of a more complex interplay between deliberative and affective influences, despite the fact that evidence suggests that the strength of the associations among deliberative and affective components of risk perceptions may be as important as the absolute magnitudes of those constructs. For example, choice preference strength and readiness for action may be strongest among individuals when deliberative and affective perceptions are in convergence [40]. These data suggest the possibility that a coherent risk perception schema, demonstrated by logical associations between the deliberative and affective risk perceptions, may be just as or more important than the absolute level of risk perceptions and worry.

Complex interactions between affective and deliberative risk perception components are also important to consider. There may be a combination of risk perceptions that could result in optimal - or non-optimal - decisions. Research suggests that deliberative and affective risk perception components may indeed interact in this way, such that individuals who are worried about an outcome and perceive themselves to be at high risk for that outcome are less motivated or less likely to engage in preventive or mitigating behaviors. For example, data from nationally representative surveys of U.S. adults indicate that those reporting both high risk perceptions and high worry were significantly less likely to engage in any exercise or meet the 5-a-day fruit and vegetable consumption guidelines [52], and were more likely to report avoiding visiting their healthcare provider even when they believe they should [53]. Although these data are cross-sectional, longitudinal data also support this pattern: in the context of a smoking cessation intervention, and using a longitudinal design, data suggest that high risk perceptions and worry contribute to lower intentions to quit smoking among adults [54].

Curr Opin Psychol. Author manuscript; available in PMC 2016 October 01. 
This pattern may emerge because high levels of affective and deliberative risk perceptions, in combination, activate specific experiential perceptions related to fatalistic beliefs about disease risk. However, as a caution against suggesting that the association between affective and deliberative risk perceptions is simple, we note that the pattern of this interaction is not always consistent [54-55], emphasizing the importance of leveraging a risk perception framework that could guide research to identify conditions under which, and populations for whom, the interaction occurs. In sum, although more research is necessary, empirical evidence suggests that disentangling deliberative, affective, and experiential components of risk perception is insufficient: interactions and associations among these components are critical to consider to maximize the predictive validity of these constructs and the efficacy of health behavior change interventions they inform.

\section{Concluding remarks}

Health-related risk perceptions play an important role in motivating health behavior change [6], and empirical evidence suggests that there are three distinct types of risk perceptions: deliberative, affective, and intuitive [38-41] . Much is known about the formation of deliberative health-related risk perceptions, including the role of numeracy, previous experiences and salient instances of the threat, and emotion. Moreover, research has examined the implications of accurate - and inaccurate - deliberative risk perceptions in health behaviors and outcomes. However, a dearth of research addresses the formation of affective and experiential health-related risk perceptions, and no research conceptualizes unrealistic optimism about risk perceptions using these non-deliberative judgments. Thus, future research is needed to further elucidate these topics, as well as to examine how deliberative, affective, and experiential risk perceptions interact to produce health behavior and health behavior change.

\section{References}

1. Rogers RW. A protection motivation theory of fear appeals and attitude change. Journal of Psychology: Interdisciplinary and Applied. 1975; 91:93-114.

2. Becker MH. The health belief model and sick role behavior. Health Education Monographs. 1974; 2(4):409-419.

3. Brewer NT, Chapman GB, Gibbons FX, Gerrard M, McCaul KD, Weinstein ND. Meta-analysis of the relationship between risk perception and health behavior: the example of vaccination. Health Psychology. 2007; 26:136. [PubMed: 17385964]

4. Floyd DL, Prentice-Dunn S, Rogers RW. A meta-analysis of research on protection motivation theory. Journal of Applied Social Psychology. 2000; 30:407-429.

5. Noar SM, Zimmerman RS. Health Behavior Theory and cumulative knowledge regarding health behaviors: are we moving in the right direction? Health education research. 2005; 20(3):275-290. [PubMed: 15632099]

**6. Sheeran P, Harris PR, Epton T. Does heightening risk appraisals change people's intentions and behavior? A meta-analysis of experimental studies. Psychological Bulletin. 2014; 140:511. This quantitative synthesis of the literature demonstrates that when interventions successfully increase risk perceptions (both deliberative and affective, examined independently), subsequent increases in behavioral intentions and health behavior change are produced. [PubMed: 23731175]

7. Persoskie A, Ferrer RA, Nelson WL, Klein WM. Precancer Risk Perceptions Predict Postcancer Subjective Well-Being. Health Psychology. 2014 ePub ahead of print. 
8. Radcliffe NM, Klein WM. Dispositional, unrealistic, and comparative optimism: Differential relations with the knowledge and processing of risk information and beliefs about personal risk. Personality and Social Psychology Bulletin. 2002; 28(6):836-846.

9. Grenen E, Ferrer RA, Klein WMP, Han P. General and specific cancer risk perceptions: How are they related? Journal of Risk Research. in press.

10. Taber JM, Klein WM, Ferrer RA, Lewis KL, Biesecker LG, Biesecker BB. Dispositional Optimism and Perceived Risk Interact to Predict Intentions to Learn Genome Sequencing Results. Health Psychology. 2014 just-accepted.

11. Fowler SL, Geers AL. Dispositional and comparative optimism interact to predict avoidance of a looming health threat. Psychology \& Health. 2014:1-34. ePub ahead of print.

12. Reyna VF, Nelson WL, Han PK, Dieckmann NF. How numeracy influences risk comprehension and medical decision making. Psychological Bulletin. 2009; 135:943. [PubMed: 19883143]

13. Peters E, Västfjäll D, Slovic P, Mertz CK, Mazzocco K, Dickert S. Numeracy and decision making. Psychological Science. 2006; 17(5):407-413. [PubMed: 16683928]

14. Brewer NT, Weinstein ND, Cuite CL, Herrington JE Jr. Risk perceptions and their relation to risk behavior. Annals of Behavioral Medicine. 2004; 27:125-130. [PubMed: 15026296]

15. Mills B, Reyna VF, Estrada S. Explaining contradictory relations between risk perception and risk taking. Psychological Science. 2008; 19:429-433. [PubMed: 18466401]

16. Tversky A, Kahneman D. Availability: A heuristic for judging frequency and probability. Cognitive Psychology. 1973; 5:207-232.

17. Chen LS, Kaphingst KA. Risk perceptions and family history of lung cancer: Differences by smoking Status. Public health genomics. 2010; 14(1):26-34. [PubMed: 20375490]

18. Slovic P. Perception of risk. Science. 1987; 236:280-285. [PubMed: 3563507]

19. Shepperd JA, Findley-Klein C, Kwavnick KD, Walker D, Perez S. Bracing for loss. Journal of Personality and Social Psychology. 2000; 78(4):620. [PubMed: 10794370]

20. Lerner JS, Keltner D. Beyond valence: Toward a model of emotion-specific influences on judgement and choice. Cognition \& Emotion. 2000; 14:473-493.

21. Mathur S, Levy M. Lung cancer risk perception and distress: difference by smoking status, and role of physical activity and race among US population. Epidemiology, Biostatistics and Public Health. 2013; 10

22. Keller PA, Lipkus IM, Rimer BK. Depressive realism and health risk accuracy: The negative consequences of positive mood. Journal of Consumer Research. 2002; 29(1):57-69.

*23. Ferrer, RA.; Klein, WMP.; Lerner, JS.; Reyna, V.; Keltner, D. Emotions and health decision making: Extending the Appraisal Tendency Framework to improve health and health care. In: Roberto, C.; Kawachi, I., editors. Behavioral Economics and Public Health. Oxford University Press; New York, NY: in pressTo appear inThis paper extends the Appraisal Tendency Framework, a framework that explains the role of discrete emotions in judgment and decisionmaking, including risk perceptions, to health behaviors. The theory posits that discrete emotions such as anger and fear have very different influences on risk perception. For example, anger is a high certainty and control emotion that results in optimistic risk perceptions, whereas fear is a low certainty and control emotion that results in pessimistic risk perceptions

24. Denes-Raj V, Epstein S. Conflict between intuitive and rational processing: When people behave against their better judgment. Journal of Personality and Social Psychology. 1994; 66:819-829. [PubMed: 8014830]

25. Tversky A, Kahneman D. Extensional versus intuitive reasoning: The conjunction fallacy in probability judgment. Psychological review. 1983; 90(4):293.

26. Gerrard M, Gibbons FX, Houlihan AE, Stock ML, Pomery EA. A dual-process approach to health risk decision making: The prototype willingness model. Developmental Review. 2008; 28(1):2961.

27. Loewenstein GF, Weber EU, Hsee CK, Welch N. Risk as feelings. Psychological Bulletin. 2001; 127:267-286. [PubMed: 11316014]

28. Slovic P, Finucane ML, Peters E, MacGregor DG. Risk as analysis and risk as feelings: Some thoughts about affect, reason, risk, and rationality. Risk Analysis. 2004; 24:1-12. [PubMed: 15027996] 
29. Loewenstein, GF.; Lerner, JS. The role of affect in decision making. In: Davidson, R.; Scherer, K.; Goldsmith, H., editors. Handbook of affective science. Oxford University Press; New York: 2003. p. 619-642.

30. Hay JL, McCaul KD, Magnan RE. Does worry about breast cancer predict screening behaviors? A meta-analysis of the prospective evidence. Preventive Medicine. 2006; 42:401-408. [PubMed: 16626796]

31. Damasio, AR. Descartes' error: Emotion, reason, and the human brain. Avon Books; New York: 1994.

32. Sinclair M, Ashkanasy NM, Chattopadhyay P. Affective antecedents of intuitive decision making. Journal of Management \& Organization. 2010; 16(3):382-398.

33. Windschitl PD. Judging the accuracy of a likelihood judgment: The case of smoking risk. Journal of Behavioral Decision Making. 2002; 15(1):19-35.

34. Weinstein ND, Kwitel A, McCaul KD, Magnan RE, Gerrard M, Gibbons FX. Risk perceptions: Assessment and relationship to influenza vaccination. Health Psychology. 2007; 26:146-151. [PubMed: 17385965]

**35. Reyna VF. Risk perception and communication in vaccination decisions: a fuzzy-trace theory approach. Vaccine. 2012; 30(25):3790-3797. This paper applies fuzzy trace theory to vaccination decisions. Fuzzy trace theory posits that individuals make decisions based on background knowledge, mental representations of verbatim and gist information, retrieval of values, and application of values to a given context. [PubMed: 22133507]

36. Janssen E, van Osch L, de Vries H, Lechner L. Measuring risk perceptions of skin cancer: Reliability and validity of different operationalizations. British Journal of Health Psychology. 2011; 16:92-112. [PubMed: 21226786]

37. Klein WMP, Harris PR, Ferrer RA, Zajac LE. Feelings of vulnerability in response to threatening messages: Effects of self-affirmation. Journal of Experimental Social Psychology. 2011; 46:12371242.

**38. Dillard AJ, Ferrer RA, Ubel PA, Fagerlin A. Risk perception measures' associations with behavior intentions, affect, and cognition following colon cancer screening messages. Health Psychology. 2012; 31:106. This study demonstrated that experiential risk perceptions were most predictive of colon cancer screening intentinos and attitudes, compared to absolute and comparative risk perceptions. However, comparative risk perceptions were most predictive of worry about colon cancer. [PubMed: 21806302]

*39. Janssen E, Waters EA, van Osch L, Lechner L, de Vries H. The importance of affectively-laden beliefs about health risks: the case of tobacco use and sun protection. Journal of behavioral medicine. 2012:1-11. In two prospective studies, experientially-derived risk perceptions predicted health-related intentions and behaviors more robustly than did deliberatively-derived risk perceptions.

40. Ferrer RA, Hall KL, Portnoy DB, Ling BS, Han PKJ, Klein WMP. Relationships among health perceptions vary depending on stage of readiness for colorectal cancer screening. Health Psychology. 2011; 30(5):525-535. [PubMed: 21534672]

41. Lipkus IM, Klein WMP, Skinner CS, Rimer BK. Breast cancer risk perceptions and breast cancer worry: what predicts what? Journal of Risk research. 2005; 8(5):439-452.

42. Weinstein ND. Unrealistic optimism about future life events. Journal of personality and social psychology. 1980; 39(5):806.

**43. Shepperd JA, Klein WM, Waters EA, Weinstein ND. Taking stock of unrealistic optimism. Perspectives on Psychological Science. 2013; 8(4):395-411. This article reviews the literature on unrealistic optimism, delineating comparative from absolute optimism and addressing recently voiced concerns about the construct of unrealistic optimism. [PubMed: 26045714]

44. Waters EA, Klein WM, Moser RP, Yu M, Waldron WR, McNeel TS, Freedman AN. Correlates of unrealistic risk beliefs in a nationally representative sample. Journal of Behavioral Medicine. 2011; 34(3):225-235. [PubMed: 21110077]

45. Dillard AJ, Midboe AM, Klein WM. The dark side of optimism: Unrealistic optimism about problems with alcohol predicts subsequent negative event experiences. Personality and social psychology bulletin. 2009 
46. Dillard AJ, McCaul KD, Klein WM. Unrealistic optimism in smokers: Implications for smoking myth endorsement and self-protective motivation. Journal of Health Communication. 2006; 11(S1):93-102. [PubMed: 16641076]

47. Ferrer RA, Klein WM, Zajac LE, Sutton-Tyrrell K, Muldoon MF, Kamarck TW. Unrealistic optimism is associated with subclinical atherosclerosis. Health Psychology. 2012; 31:815. [PubMed: 22429124]

48. Katapodi MC, Dodd MJ, Lee KA, Facione NC. Underestimation of breast cancer risk: influence on screening behavior. Oncology Nursing Forum. 2009; 36:306-314. [PubMed: 19403452]

49. Gramling R, Klein W, Roberts M, Waring ME, Gramling D, Eaton CB. Self-rated cardiovascular risk and 15-year cardiovascular mortality. The Annals of Family Medicine. 2008; 6(4):302-306. [PubMed: 18626029]

50. Hevey D, McGee HM, Horgan JH. Comparative optimism among patients with coronary heart disease (CHD) is associated with fewer adverse clinical events 12 months later. Journal of Behavioral Medicine. 2014; 37:300-307. [PubMed: 23274764]

51. Taylor SE, Kemeny ME, Aspinwall LG, Schneider SG, Rodriguez R, Herbert M. Optimism, coping, psychological distress, and high-risk sexual behavior among men at risk for acquired immunodeficiency syndrome (AIDS). Journal of Personality and Social Psychology. 1992; 63:460. [PubMed: 1403625]

52. Ferrer RA, Portnoy DB, Klein WMP. Higher cancer-related worry and risk perceptions are related to lower exercise and fruit and vegetable consumption: Results from the Health Information National Trends Survey. Journal of Health Communicatio. 2013; 18:397-409.

53. Persoskie A, Ferrer RA, Klein WM. Association of cancer worry and perceived risk with doctor avoidance: an analysis of information avoidance in a nationally representative US sample. Journal of behavioral medicine. 2014; 37(5):977-987. [PubMed: 24072430]

54. Klein WMP, Zajac LE, Monin MM. Worry as a moderator of the association between risk perceptions and quitting intentions in young adult and adult smokers. Annals of Behavioral Medicine. 2009; 38:256-261. [PubMed: 20049660]

55. Portnoy DB, Kaufman AR, Klein WM, Doyle TA, de Groot M. Cognitive and affective perceptions of vulnerability as predictors of exercise intentions among people with type 2 diabetes. Journal of Risk Research. 2013; 17:177-193. [PubMed: 24563609] 


\section{Highlights}

- Interventions that change risk perceptions subsequently change health behaviors

- Individuals form risk perceptions tailored to specific health threats

- Risk perceptions can refer to deliberative, affective, and experiential components

- These components can interactively influence health behaviors.

- The formation of accurate risk perceptions has implications for health behaviors 